\title{
INTEGRATING ELECTROMAGNETIC FUNCTIONS INTO FIBER METAL LAMINATES - THE STRUCTURAL CHALLENGE
}

\author{
- EMuS 2019 - \\ CEES VAN HENGEL ${ }^{*}$, CHARLY HEUTS ${ }^{\dagger}$ AND JACO VERPOORTE ${ }^{n}$ \\ * Fokker Aerostructures \\ Industrieweg 4, 3351 LB Papendrecht, Netherlands \\ cees.vanhengel@fokker.com \\ $\dagger$ Fokker Elmo \\ Aviolandalaan 33m 4631 RP, Netherlands \\ charly.heuts@fokker.com \\ ${ }^{\mathrm{n}}$ Netherlands Aerospace Centre (NLR) \\ Voorsterweg 31, 8316 PR Marknesse, Netherlands \\ jaco.verpoorte@nlr.nl
}

Keywords: GNSS, VHF, FML, Integrated Antenna, Glare

\begin{abstract}
:
This paper outlines aspects, outcome and prospects of full integration of antennas into structural elements of aircraft, from a structural design perspective.

\section{INTRODUCTION}

Currently, antennas on civil aircraft are typically not integrated but externally mounted items. Firstly this causes aerodynamic drag resulting in increased fuel use. Secondly, conventional antennas are subject to in-flight damage by hail, lightning strike and also by ground handling. Integration of antennas holds the potential to remove the drag issue, and reduce the impact damage sensitivity as well. Thirdly, a smooth fuselage may also offer esthetic appeal which may be appreciated by discerning customers of top level business jets.

In view of these benefits, integration of antennas is the subject of research such as in the European ACASIAS project. The aim is full integration, i.e. to making the antenna function an integral part of the structural component. Structural components in this regard are meant to be structural aircraft elements that fulfil a load-bearing function.
\end{abstract}

A particularily interesting material type for the antenna integration purpose are Fiber Metal Laminates or FMLs. An FML is a hybrid composite aircraft construction material, consisting 
of fiber layers that are bonded together with metal layers to form a cohesive laminate. This construction material has been developed especially to improve metal fatigue properties of aircraft construction material. As it turns out, this material also lends itself to be morphed into an antenna. However, the electromagnetic functioning of an antenna, and its associated design, are outside the scope of the present paper.

Two types of antenna, which enable integration within an aircraft fuselage skin, have been chosen for the present research; each antenna for a different application in terms of operating frequency and direction of radio wave propagation. The smaller of the two is a GNSS (Global Navigation Satellite System) antenna, as described in the paper by Konter et.al. [1]. This antenna is of limited structural complexity and will not be further discussed here. The larger of the two is a VHF antenna, which has the potential to cause major disruption to the fuselage structure, making the integration significantly more challenging. The structural integration of the VHF antenna will therefore be the main topic of this paper.

\section{FMLS- A BRIEF INTRODUCTION}

Fiber Metal Laminates are a class of hybrid materials consisting of aluminium layers bonded together with epoxy adhesive reinforced by high strength unidirectional glass fibres, see Fig. 1. The material is produced in a composite like process, namely by precisely placing the ingredient aluminium and glass-fibre prepreg plies in a predefined way on top of each other on a curved aluminium lay-up mold. Following lay-up, the laminate is consolidated in an autoclave by curing under pressure and temperature. The resulting material has aluminium-like

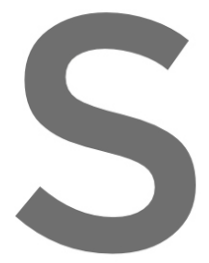
characteristics, makint such as used in the airt
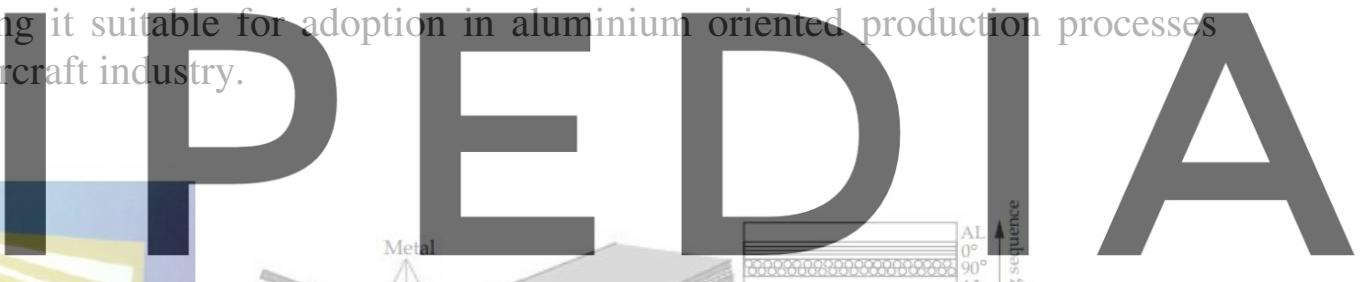

Register for free at https//www.scipedia.com to download the version without the watermark
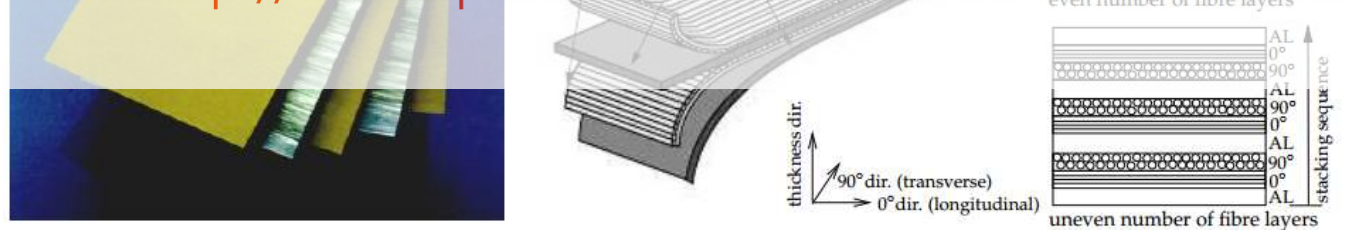

Figure 1: FML laminate ingredients (left) and typical laminate lay-up and stacking sequence

The mechanical properties that result from the judicious combination of the aluminium and GRP layers include very slow fatigue crack growth, high static strength and high impact resistance. In addition, the electrical conductivity of the metal layers provides lightning protection and EMI shielding. Furthermore, the glass-epoxy layers provide corrosion resistance and aid burn-through resistance (Fig. 2). 

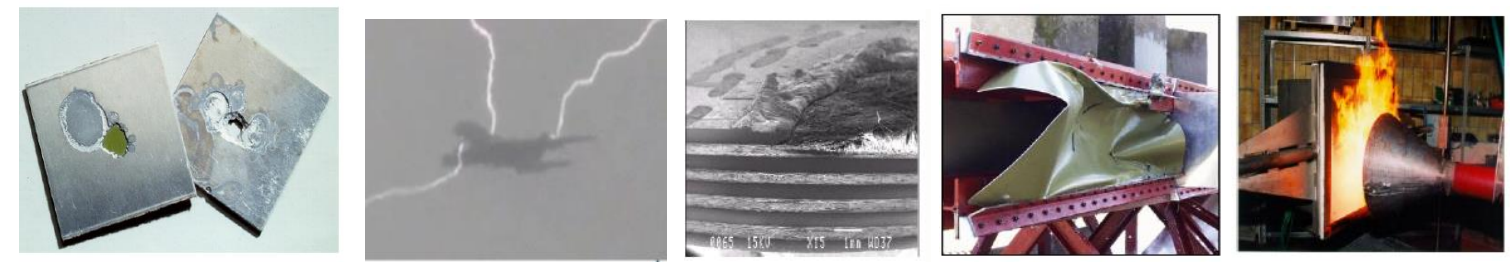

Figure 2: FML materials property illustrations (from left): corrosion resistance, lightning strike event and localized material damage, impact resistance (leading edge development test), and burn-through resistance

Also, the composite-like nature of the FML material concept provides a composite-like design freedom with respect to fiber orientation and laminate thickness variation. As demonstrated on the Airbus A380, where approx. $460 \mathrm{~m}^{2}$ of the material is applied as 27 large fuselage skin panels, the combination of this design freedom, the FML material properties, and the manufacturing process enable aircraft designers to achieve significant weight savings at costs that are competitive with aluminium $[2,3]$.

Last but not least the aluminium-like character of FMLs also brings with it another benefit. As demonstrated by many years of flight testing on an Airbus A310 of the German Air Force during the development of FML in the late 90's and early 00's, the aluminium-like characteristic of FML material makes it relatively easy to replace an aluminium skin panel of an existing aircraft by an FML panel (Fig. 3). This fact may greatly simplify the future introduction for testing or operational use of integrated antennas on existing aircraft.

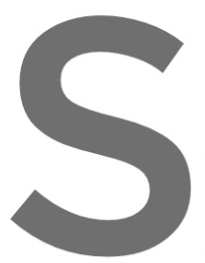

All in all, FMLs nal structure
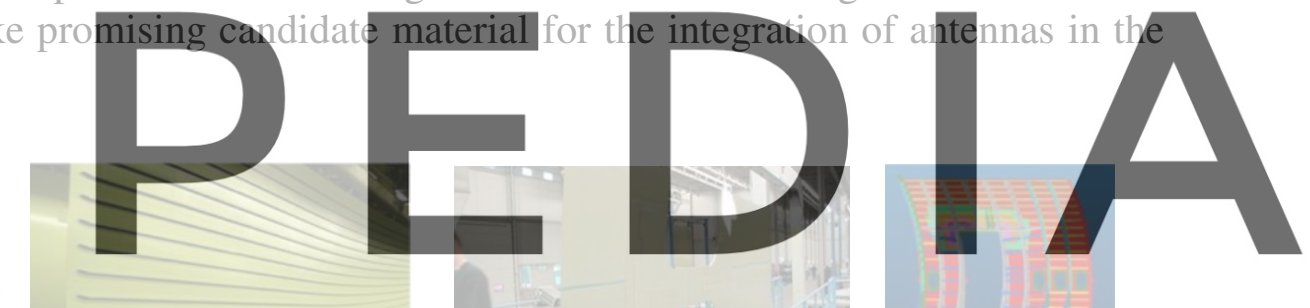

ree at https//www.scipedia.com to download the version without the watermark
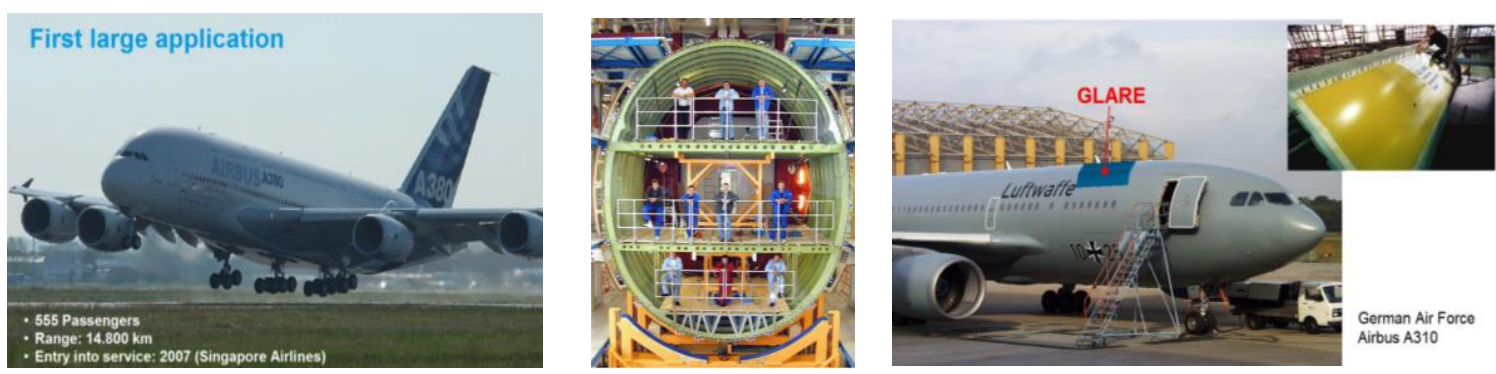

Figure 3: FML Glare application examples (clockwise from top left): Glare FML panels on A380, FML panel with stringers and window cut-outs, FML door panel, door panel design, developmental Glare test panel flown on A310, A380 fuselage cross section (Megaliner Barrel test), A380 take-off 


\section{VHF ANTENNA: CUT-OUT GEOMETRY}

From an antenna design perspective, a slot antenna is an elegant solution to enable a flush (non-protruding) antenna. Since for VHF-COM the electromagnetic fields needs to be vertically polarized, the laws of electromagnetism require that the slot is oriented horizontally. This kind of geometry is show in Fig. 4. A VHF antenna operates at a relatively low electromagnetic frequency (approx. $100 \mathrm{MHz}$ ) and since the slot length is determined primarily by the frequency, this results in a slot length of approx. 0.8 to $1.2 \mathrm{~m}$ depending on the antenna materials. Aircraft fuselages are typically semi-monocoque structures, where circular frames and straight stringers support the skin which is the main load carrying structural element. For commercial aircraft that fly at a height of approx. $10 \mathrm{~km}$, the cabin section of the fuselage is pressurized to approx. 0.5 bar or more of overpressure in flight, which results in high circumferential (and lesser axial) loads in the skin.

In these circumstances, from a structural perspective, creating a horizontal slot in the skin is about the worst possible "damage" that can be done to the structure. Detailed FEM analyses [2] of early design studies showed the high deformations and stresses that can occur due to the pressurization load, and highlighted the need for proper attachment of stringers and frames in the cut-out area.
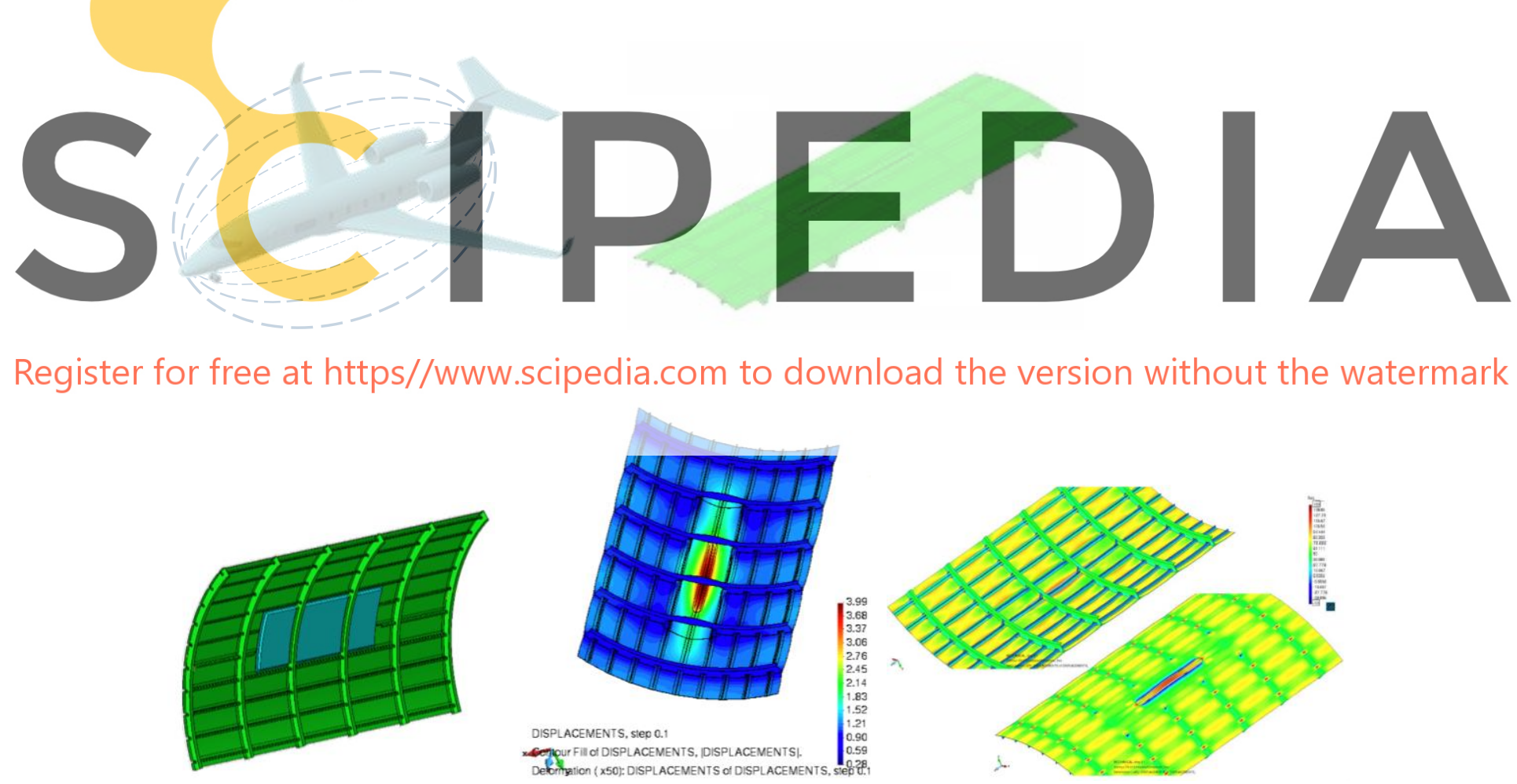

Figure 4: Slot antenna lay-out (early concept studies and FEM analyses [4]) 


\section{SKIN LOAD PATH CONTINUITY}

A fuselage typically contains many cut-outs, such as passenger doors, emergency exits and windows, so the antenna slot is not unique in disturbing skin load path continuity. However, to keep the antenna commercially attractive, the added weight and cost of integration must be kept small, and therefore the kind of reinforcements needed for doors etc. are not acceptable. Fortunately the antenna slot needs only to be present in the aluminium part of the FML layers, and the slot gap can therefore be bridged by continuous glass layers since these are electromagnetically transparent. Additional glass layers are added for sufficient strength (Fig. 5). The most effective build-up is currently under investigation.

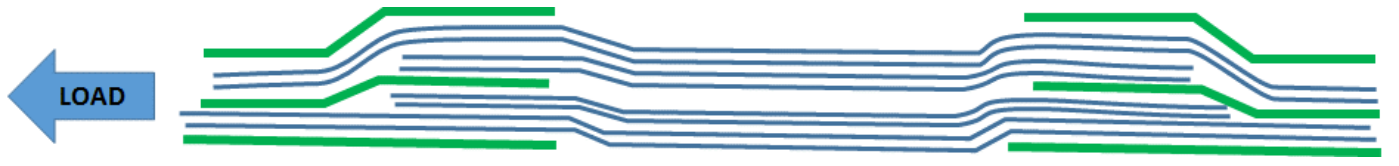

Figure 5: Transition from FML to «full glass» GFRP to FML (concept)

\section{CERTIFICATION ASPECTS}

Aircraft need to meet stringent airworthiness requirements before they are allowed to fly. Since an integrated slot antenna, if ever applied, will definitely come under the scrutiny of the airworthiness authorities, it is wise to consider the airworthiness requirements early in the development. A time proven approach to meetstrength requirements is the so-called Building Block testing pyramid approach as shown in fig. 6. This approneh goes from testing a large
number of (cheap) small test specimen, at the material level, up to testing only one or two very
large and expensive test specimens at the component level (such as a wing or fuselage section).

Register for free at https//www.scipêّidia.com to downloâd the version without the watermark

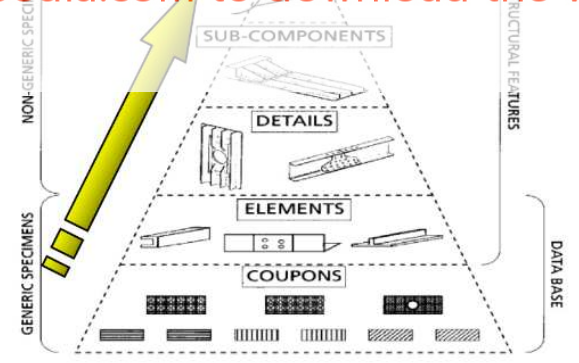

Figure 6: Building Block test Pyramid

This approach will also be followed for structural testing of the integrated antenna. In line with the low-TRL level of the current project, the anticipated highest level is that of "details" (Fig. 7). 

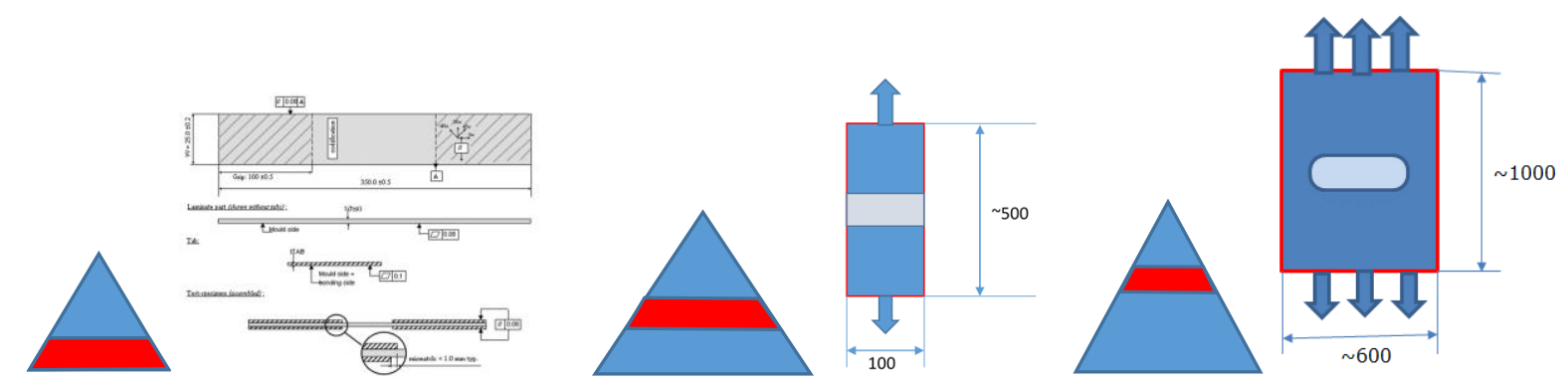

Figure 7: Building Block tests planned for Integrated Antenna (from left): coupon testing for material characterization, structural element testing of FML-GFRP-FML transition, «full scale» panel test

\section{CONCLUDING REMARKS}

The structural aspects have been outlined of an Integrated Slot Antenna in an FML fuselage skin. As has been shown, the FML material offers numerous advantages to the realization of this concept, such as the possibility for a smooth transition from FML to full glass-fiber reinforced composite and back. The development approach selected takes into account the possibility of future airworthiness certification.

\section{ACKNOWLEDGEMENTS}

The support of CIMNE in the preparation of this paper is gratefully acknowledged.

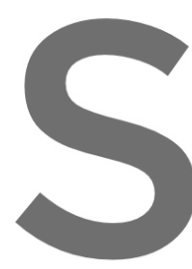

All work described in th

2020 research and innoration project.

REFERENCES
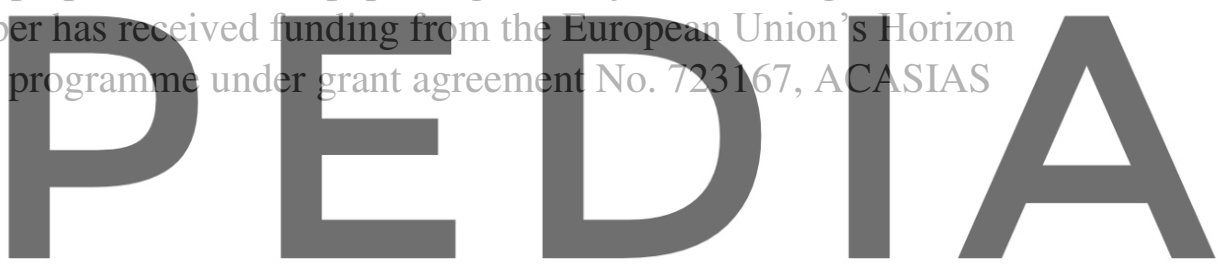

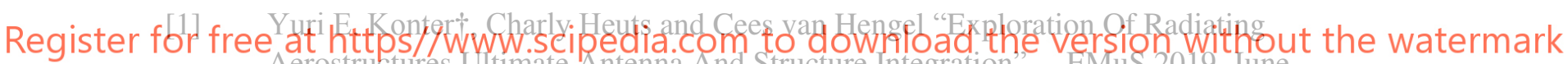
BARCELONA, Spain

[2] Hinrichsen, J.: "The Material Down-selection Process for A3XX"; Keynote Address to the "19th European Conference on Materials for Aerospace Applications", Confederation of European Aerospace Societies (CEAS), Munich, Germany Dec. 6th - 8th, 2000.

[3] Dr.-Ing. Thomas Beumler,: "Airbus Fiber Metal Laminate Structures - from Laboratory to Application", Lecture to RAeS Hamburg Branch, 29 October 2009, https://www.fzt.hawhamburg.de//pers/Scholz/dglr/hh/text_2009_10_29_Fiber_Metal_Laminates.pdf

[4] Xavier Martinez, FrancescTuron \& Fermin Otero "Homogenization procedure for the structural design of smart fuselage panels", $8{ }^{\mathrm{TH}}$ EASN-CEAS International workshop on manufacturing for growth and innovation, September 5TH, 2018, GLASGOW, UK 